\title{
Drop Performance of Dangerous Goods Packages in the Aspect of Parcel Delivery Standards
}

\author{
Ákos Mojzes ${ }^{1}$, Thomas Trost ${ }^{2}$, Kata Vöröskői ${ }^{1}$ \\ ${ }^{1}$ Széchenyi István University, Hungary, Győr, Egyetem sq. 1.9026, voroskoi.kata@sze.hu \\ ${ }^{2}$ RISE Innventia AB, Stockholm, Sweden, thomas.trost@ ri.se
}

\begin{abstract}
Requirements for dangerous goods packaging are well known, whatever version are used. The testing circumstances are strictly defined for each transportation method (road, rail, air, sea). But nowadays it is becoming a practice that courier express operators transport dangerous goods as single package. This parcel delivery method means a higher risk for all kind of logistics participants. By this service the packages are delivered fast, but handled more roughly than in comparison to LTL (less than truckload) or FTL (full truck load). Naturally, the parcel delivery sector uses its own suitability testing methods, which are also well defined. These procedures are coming from various standards such as ASTM, ISTA or corporate (FedEx) standards. This paper compares the most common parcel delivery testing conditions concerning the drop test requirements of DGR (Dangerous Goods Regulation) using packaging such as paper bag, corrugated fibreboard box, steel drum and plastic jerrycan, respectively. Then the test results were analyzed to present the differences.
\end{abstract}

Keywords: package testing, dangerous goods, parcel delivery, drop test, corrugated

\section{Introduction}

The packaging industry and their customers seek to reduce costs and environmental impact of packaging. A general trend for packaging is that the amount of material is being reduced. The dominating material for transport packaging is corrugated board of various qualities and grammages. The average grammage in Europe has been reduced from $558 \mathrm{~g} / \mathrm{m}^{2}$ in 1997 [1] to $515 \mathrm{~g} / \mathrm{m}^{2}$ in 2016 [2]. Today the proportion of recycled fibres is also quite high in corrugated products. Of the total consumption of raw materials in 2016, $28 \%$ was testliner [2]. This often means a lower quality of the corrugated board compared to the use of kraftliner made from virgin fibres.

While the material reduction continues, the packaging has to fulfil its duties. The products must be protected from humidity, dirt, shocks and vibrations. New demands are introduced with the heavily increased amounts of single packages direct to consumers due to e.g. the increased e-commerce. This has led organisations such as ISTA to develop special test schedules such as the ISTA 6-series Amazon test [3].

Several studies have been performed measuring drop heights with electronic data recorders, e.g. Singh et al reports around $70 \mathrm{~cm}$ drops occurs for $95 \%$ of the packages with weight 6.8 $\mathrm{kg}$ shipped between Michigan and California in USA. The results naturally had a variation for the three different postal services studied (DHL, UPS and FedEx). The reality for the large flow packages today is that they are handled both manually during collection and delivery and on large high-speed conveying and sorting equipment at hubs [4]. 
Garcia-Romeu-Martinez et al. claims to be the first study to determine the international handling and shipping environment of single parcels between two continents. Transport tests were performed between Valencia (Spain) and Michigan (US). Based on several measurements the authors recommend designing for load levels covering $95 \%$ of the cases. For example, a package will likely experience an average of 27 drops in an international express parcel shipment, and $95 \%$ of these drops will occur below a drop height of $0.57 \mathrm{~m}$. Later several international studies have been performed [5].

One example is Böröcz and Singh which measured the physical and climatic conditions during transportation and handling (vibration, shocks, temperature and relative humidity) in a less-than-truckload unit shipped via multiple transport modes (truck and vessel) between two companies and two continents, from Hungary to South Africa. The shipment consisted of electrical automotive parts. This study does not examine the effect of vehicles used, their velocity, the road conditions and the different payloads but reports on the measured levels of physical and climatic hazards through the whole trip as a collective international multi-modal shipment. One of the conclusions was (the already known fact) that the transportation environment specific to truck vibration levels in Central Europe was lower than those measured in North America [6].

Singh et al studied 'air package shipment' conditions experienced by packages transported by air under 'normal conditions of transport'. Air package shipment data (temperature, humidity, pressure, shock and vibration) were collected for several domestic and international routes through instrumented packages. The collected data were supplemented by previous research to measure and quantify this multi-modal shipping environment. This study also compared industry-accepted American Society for Testing and Materials (ASTM) pre-shipment test methods with the general requirements of package design qualification testing as outlined in 49 Code of Federal Regulations (CFR). This review revealed that the design qualification testing for certain distribution-related hazard elements is not currently representative of the normal conditions of air transport. The data gathered in this study were analysed to represent the current 'normal conditions of transport', i.e. beginning-to-end delivery of air packages. The study used the time spent by the package in each of the segments of transportation to determine a 'single profile' or 'test' that would represent the average and normal expected levels for each hazard element and would serve as the basis of a minimum level for performance testing to establish normal conditions of transport by air. The recommended test methods and levels are claimed to be easily adopted by existing distribution packaging testing labs globally [7].

Appleton compiled and interpreted drop heights and drop frequencies data for small parcel packages (weighing less than $100 \mathrm{lb}(45.4 \mathrm{~kg})$ ) moving through the Eastman Kodak Company global distribution network. Dummy load packages were used in shipments in the United States, Europe, and Australia. The test packages were equipped with a drop-height recording device called a SAVER (Shock and Vibration Environmental Recorder, Lansmont Corp., USA) to record when a drop occurred and from what height the package was dropped. The results of the analysis led to modified drop test schedules within Eastman Kodak avoiding overtesting and overpacking [8].

Stevenson investigated the frequency and magnitude of free-fall drops, tosses and impacts encountered by a small package during overnight air transportation between Memphis, Tennessee and Gennevilliers, France. The package was instrumented with a data recorder to 
measure and record the events experienced by the package. The largest drop occurred from a height of 51 inches $(130 \mathrm{~cm})$ and the largest toss occurred from a height of 75 inches $(190$ $\mathrm{cm})$ [9].

Zhong et al. made an ambitious study of the express shipping industry in China, which has developed rapidly in recent years. Express shipping is dedicated to small packages. This package type, which is classified as transport package, has a high risk of product damage because of its characteristics [10].

Several studies have been performed combining drop heights with other parameters such as air pressure etc with electronic data recorders, e.g. Singh et al [7]. An interesting study of drop tests of jerrycans were presented by Menrad et al, where guided drop tests were performed to achieve defined and reproducible impact orientations. The drop heights where $50 \%$ of the jerrycans experienced a failure from a crack where fluid can escape $(50 \%$ failure drop height) were compared among jerrycans made of four different materials, in their original state and preconditioned with standard liquids [11].

With consumer e-commerce shipments increasing globally by 33\% between 2014 and 2016 according to Smithers Pira, this distribution channel is fast developing from a niche to a volume application [12]. The increased e-commerce will especially increase the demand of corrugated according to research by Fisher International [13].

\section{Comparison of drop test methods}

Attention should be paid to possible sources of handling drops or impacts. A block diagram of how a package travels from manufacture to consumption is a useful tool to develop. With these observations, targets for the measurement steps may be selected. A certain handling operation, or a transportation mode or route, or an entire trip or system, may be selected. Independent variables, such as position in the vehicle or weight of package may be targeted at this stage. The time between drops in actual shipment may range from minutes to days, so time compression is needed. In the laboratory simulation, drops are conducted with minimal waiting time, so the elapsed time is compressed. Rather than a series of drops all at the same drop height, a series should be constructed with different drop heights, because that is how drops happen in actual handling. This is modeled on the actual hazard, where high drop heights occur seldom, and lower drops occur more often [14]. One of the packages primary functions is, beside protecting the product is containment. One common end point for drop tests are when the product falls out or spills from the package [15]. Containment is a key issue, especially for dangerous cargo.

Already e.g. Kellicutt and Landt investigated drop tests with different orientations on the box [16]. Kellicutt investigated the drop test procedure closer [17]. The test method is attractive due to its simplicity and that it closely mimics several of the hazards encountered in handling and shipping. However, it is hard to get statistically sound results depending on if consecutive drops are made on the same box or if new samples are taken for every drop. The rigidity of the dropping surface is also relevant as well as the orientation of the cargo. Kellicutt also constructed a performance index based on drop test and bursting strength test and the fact that a greater weight of the box and its content causes a more severe impact when dropped on a solid surface [18].

The behavior and performance of the box during drop test is also strongly related to other 
important test methods. An interesting study presented by Poustis from drop test experiments with B flute filled RSC boxes of $40 \times 30 \times 30 \mathrm{~cm}^{3}$ showed the importance of burst values in relation to drop height. In this study test liners with burst index 2.0-2.4 gave maximum drop height of $75 \mathrm{~cm}$, while kraftliners with burst index $\geq 3.8$ gave starting drop height at $120 \mathrm{~cm}$ and maximum drop height at $230 \mathrm{~cm}$ [19].

Commonly drop tests mimicking packages, which are normally handled manually are performed as free-fall, e.g. ASTM D5276 [20] or ISO 2248 [21]. Due to problems with reproducibility there are also other ways to obtain the desired shock on the package, e.g. with shock machines e.g. according to ASTM D880 [22] or TAPPI 802 [23]. There is also a possibility to use inclined (or horizontal) impact e.g. according to ASTM D4003 [24]. Some test methods are specifically aiming at e-commerce packaging, e.g. ISTA 3A [25] which is a general simulation performance test for packaged products weighing less than $150 \mathrm{lbs}$. According to ISTA, this is the test for e-commerce shipments consisting of multiple products.

\subsection{DGR}

In case of dangerous goods transportation, the regulations divide the goods and materials when they are packed, into three packaging groups (Packing group I: Substances presenting high danger; Packing group II: Substances presenting medium danger; and Packing group III: Substances presenting low danger).

Other details, like packed quantity, volume and density will influence the testing parameters. Beside the characteristics of danger, the quantity of packed dangerous material is one of the most important parameter. The Dangerous Goods Regulation (DGR) define three versions of packages, which may appear as parcel delivered packages.

a) Packages for Excepted quantities (EQ): The substance of dangerous goods in this version is the smallest. Practically it means just few grams or milliliters (1-30 g or ml) per inner packaging and max 300 to $1000 \mathrm{~g}$ or ml per outer packaging. The regulations also define the assembly and the components of the product- package system (inner packaging, closing, rigid intermediate packaging with cushioning and absorbent components, rigid outer package).

b) Packages for Limited quantities (LQ): This category allows to apply more dangerous substances (just for the allowed materials), but more of provisions must be taken into account. Practically it means $500 \mathrm{~g}$ to $5 \mathrm{~kg}$ dangerous goods per inner packaging. The regulations also define the maximum gross mass of a transport package. For rigid wall outer packages, it means maximum $30 \mathrm{~kg}$.

c) Normal packages $(\mathrm{P})$ : In this packaging category the weight or volume is maximized to $\max 450 \mathrm{~kg}$ or 450 liters. High variation of packaging devices can be used, like single packages, combination packages, composite packages. The regulations clearly define permitted materials (with UN number) as a packaging material, constructions, etc.

The different regulations for different transport modes (UN DGR, ADR, RID, IMDG, IATA DGR) mention 3534 pieces or items with UN number. In the real life the number of dangerous goods items combinations is higher. By this, the variation of packaging types is huge. In Table 1, we have summarized the drop details of each of the above mentioned categories. In case of single packages and liquid filling materials the density is very important, it affects the drop height. To reduce the variations, Table 1 is suitable just in case 
of solids and for limited type of packages (boxes). In case of other packaging types, the number of dropped samples, the test sequence and the drop orientations may differ.

Table 1. Comparison of drop test details for different dangerous good quantities.

\begin{tabular}{|c|c|c|c|}
\hline Category & a) & b) & c) \\
\hline $\begin{array}{c}\text { Acronym of } \\
\text { packaging version }\end{array}$ & EQ & LQ & $\mathrm{P}$ \\
\hline Description & $\begin{array}{l}\text { Corrugated Fibre } \\
\text { Board (CFB) box } \\
+ \text { intermediate and } \\
\text { inner packages }\end{array}$ & $\begin{array}{c}\text { CFB outer box }+ \text { inner } \\
\text { packages }\end{array}$ & $\begin{array}{c}\text { CFB outer box }+ \text { inner } \\
\text { packages }\end{array}$ \\
\hline Filling material & solid & solid & solid \\
\hline Gross mass [kg] & $1 *$ & $\max 30^{*}$ & $\max 450 *$ \\
\hline Drop height [m] & 1,8 & 1,2 & $0,8 / 1,2 / 1,8$ \\
\hline Drop sequence & $\begin{array}{c}\text { - flat on the base; } \\
\text { - flat on the top; } \\
\text { - flat on the longest } \\
\text { side; } \\
\text { - flat on the shortest } \\
\text { side; } \\
\text { - on a corner; }\end{array}$ & & $\begin{array}{c}1^{\text {st }}: \text { flat on the bottom } \\
2^{\text {nd }}: \text { flat on the top } \\
3^{\text {rd }}: \text { flat on the long side } \\
4^{\text {th }}: \text { flat on the short side } \\
5^{\text {th }}: \text { on a corner }\end{array}$ \\
\hline Acceptance criteria & $\begin{array}{c}\text { No leakage, no damage } \\
\text { affect safety during } \\
\text { carriage }\end{array}$ & $\begin{array}{c}\text { No leakage, no damage } \\
\text { affect safety during } \\
\text { carriage } \\
\end{array}$ & $\begin{array}{l}\text { No leakage, no damage } \\
\text { affect safety during carriage }\end{array}$ \\
\hline
\end{tabular}

*net weight of dangerous goods (without packaging mass)

\subsection{Parcel delivery}

After a full test procedure, the packages must be evaluated according to requirements. Most of parcel delivery standards, as the described also, allows the shipper/client to determine what kind of damage is allowed for product and/or package.

\section{Applied packages during the tests}

In the following subsections, the description of each tested packages can be read. The description of each version is not fully detailed, but the type approvals can be requested from the authors.

\subsection{Plastic bag properties}

Dimensions: $530 \times 570 \mathrm{~mm}$ (width $\mathrm{x}$ height); $150 \mathrm{~mm}$ (width of the bottom)

Raw material: LDPE

Closure:

top: paste + valve

bottom: gluing with AD Plastic equipment (pasted)

Foil thickness: $160 \mu \mathrm{m}$

Gross dead weight: $26 \mathrm{~kg}$

UN Type approval marking: 5H4/Y26/S

\subsection{Corrugated fibreboard box}

INNER PACKAGING

Name: separator, Corrugated board type: according to specification 
Name: top and bottom sheet, type: according to specification

OUTER PACKAGING

Description: Multilayer corrugated board box (4G-ADR code of fibreboard boxes)

Dimensions (inner): 391 x 241 x $153 \mathrm{~mm}$

Empty weight: $0,46 \mathrm{~kg}$

Cardboard type: BC (Bursting strength: $1830 \mathrm{kPa}, \mathrm{ECT}: 12,55 \mathrm{kN} / \mathrm{m}$ )

Grammage: $925 \mathrm{~g} / \mathrm{m}^{2}$

Closing method: self adhesive tape $(50 \mathrm{~mm})$

Cobb $30 \mathrm{~min}$ : 138/142 g/m² outer/inner side

Gross dead weight: $10 \mathrm{~kg}$

UN Type approval marking: 4G/Y10/S

\subsection{Steel drum}

Description: steel drum packaging device, with removable head

Nominal cubic capacity: 7,6 litre

Dimensions: Ø234 x $253 \mathrm{~mm}$ (with lid) (diameter x height)

Construction: welded, and with handle, without inner plastic compartment, with gasket

Mass data:

Mass of body: $635 \pm 20 \mathrm{~g}$

Closure mass with gasket: $250 \pm 10 \mathrm{~g}$

Mass of device: $885 \pm 25 \mathrm{~g}$

Applied materials:

body: material: steel, Thickness: $0,35 \mathrm{~mm}$

closure: material: steel Thickness: $0,55 \mathrm{~mm}$, gasket: Material: PVC

UN Type approval marking: 1A2/Y11/S

\subsection{Plastic jerrycan}

Description: Plastic jerrycan with capacity $5 \mathrm{~kg}$ of solid material, with removable head

Nominal cubic capacity: 13,5 litre $(10 \mathrm{~kg})$

Dimensions: 237,1x23,7,1x307,0 mm (length $\mathrm{x}$ width $\mathrm{x}$ height)

Cap diameter: $85 \mathrm{~mm}$

Closure torque: $\min .15 \mathrm{Nm}$

Mass data:

Mass of body: $600 \pm 12 \mathrm{~g}$

Closure mass with gasket: $43,2 \mathrm{~g}$

Mass of device: $643,2 \pm 12 \mathrm{~g}$

UN Type approval marking: 3H2/Y10/S

\section{Test procedure}

The drop procedures have been done in normal climate conditions $\left(23^{\circ} \mathrm{C}, 50 \% \mathrm{RH}\right)$ and according to ISO 2233 [26]. The drop procedures have been done on a free fall drop tester (Type: Cometech QC113B1, Cometech Testing Machines Co. Ltd. - Taiwan) and the impact area was non-resilient and horizontal steel plate, according to ISO 2248.

As all of tested packages are UN type approved packages, they previously passed the drop requirements of these regulations. Even so, the drop tests according to UN regulations were one more time performed. The test sequence was the following: 
1. Drop test according to UN regulations

2. Drop tests according to ISTA 3A (standard, 1st sequence)

3. Drop tests according to FedEx requirements.

The following tables contain the drop procedure details, including heights, and impact positions. As the UN regulations differ the drop positions for more packaging types, Table 2 contains just the procedures of this. Table 3 contains the parcel delivery procedure details. (Note: The identification of faces/edges and corners has been done according to ISTA $3 \mathrm{~A}$ standard.)

Table 2. Test details of drop tests according to UN regulation.

\begin{tabular}{|c|c|c|c|c|}
\hline $\begin{array}{c}\text { Tested } \\
\text { package: }\end{array}$ & Plastic bag & CFB box & Steel drum & Plastic jerrycan \\
\hline Drop height: & \multicolumn{4}{|c|}{$1200 \mathrm{~mm}$} \\
\hline \#nr & Drop positions & Drop positions & Drop positions & Drop positions \\
\hline 1 & flat on a wide face & Bottom edge & $\begin{array}{c}\text { diagonally on the } \\
\text { chime }\end{array}$ & Bottom edge \\
\hline 2 & on an end of the \\
bag & $\begin{array}{c}\text { Vertical edge, } \\
\text { where the } \\
\text { sidewalls joined }\end{array}$ & $\begin{array}{c}\text { To the weakest } \\
\text { point (edge of } \\
\text { closure) }\end{array}$ & $\begin{array}{c}\text { To the weakest } \\
\text { point (edge of } \\
\text { closure) }\end{array}$ \\
\hline $\begin{array}{c}\text { Total number } \\
\text { of drops }\end{array}$ & $\begin{array}{c}\text { Total 3 samples } \\
\text { (2 drops per bag) }\end{array}$ & $\begin{array}{c}\text { Total 6 samples } \\
\text { (3 for each drop) }\end{array}$ & $\begin{array}{c}\text { Total 6 samples } \\
\text { (3 for each drop) }\end{array}$ & $\begin{array}{c}\text { Total 6 samples } \\
\text { (3 for each drop) }\end{array}$ \\
\hline
\end{tabular}

Table 3. Test details of drop tests according to parcel delivery standards.

\begin{tabular}{|c|c|c|c|c|}
\hline $\begin{array}{c}\text { Procedure } \\
\text { name }\end{array}$ & \multicolumn{2}{|c|}{ ISTA 3A } & \multicolumn{2}{c|}{ FedEx } \\
\hline$\# n r$ & Drop positions & Drop height & Drop positions & Drop height \\
\hline 1 & Edge 3-4 & $460 \mathrm{~mm}$ & Corner 2-3-5 & $762 \mathrm{~mm}$ \\
\hline 2 & Edge 3-6 & $460 \mathrm{~mm}$ & Edge 2-5 & $762 \mathrm{~mm}$ \\
\hline 3 & Edge 4-6 & $460 \mathrm{~mm}$ & Edge 2-3 & $762 \mathrm{~mm}$ \\
\hline 4 & Corner 3-4-6 & $460 \mathrm{~mm}$ & Edge 3-5 & $762 \mathrm{~mm}$ \\
\hline 5 & Corner 2-3-5 & $460 \mathrm{~mm}$ & Face 4 & $762 \mathrm{~mm}$ \\
\hline 6 & Edge 2-3 & $460 \mathrm{~mm}$ & Face 2 & $762 \mathrm{~mm}$ \\
\hline 7 & Edge 1-2 & $460 \mathrm{~mm}$ & Face 6 & $762 \mathrm{~mm}$ \\
\hline 8 & Face 3 & $910 \mathrm{~mm}$ & Face 5 & $762 \mathrm{~mm}$ \\
\hline 9 & Face 3 & $460 \mathrm{~mm}$ & Face 1 & $762 \mathrm{~mm}$ \\
\hline 10 & - & - & Face 3 & $762 \mathrm{~mm}$ \\
\hline
\end{tabular}

\section{Evaluation of test results}
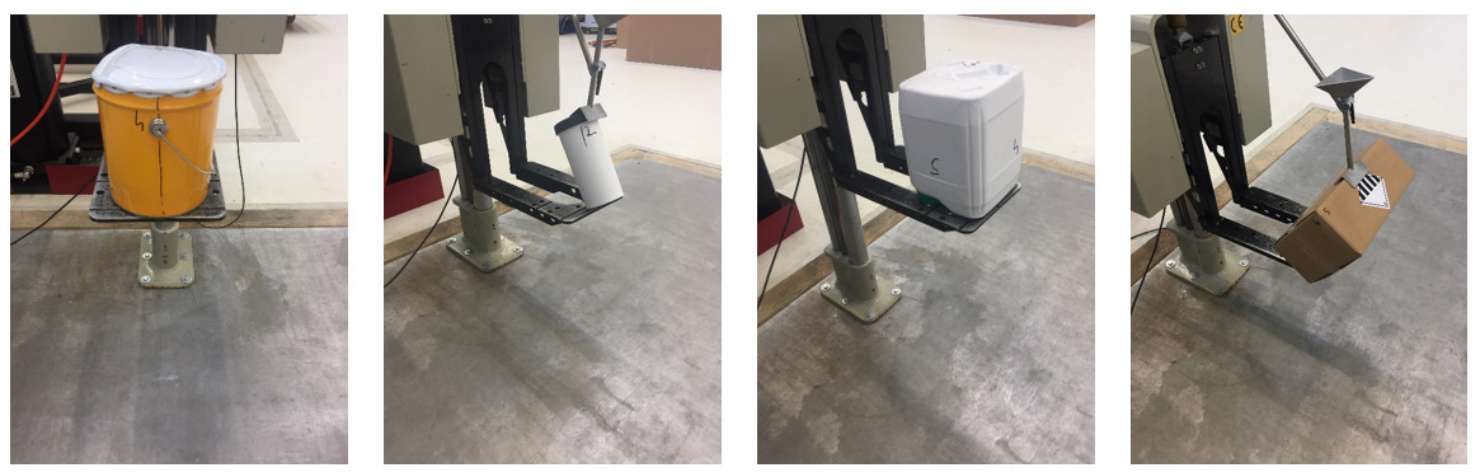

Figure 1. Examples of different drop positions. 
In Figure 1 is shown some of the drops performed. Figure 2 represents the damages on $4 \mathrm{G}$ corrugated fibreboard box along different test requirements.
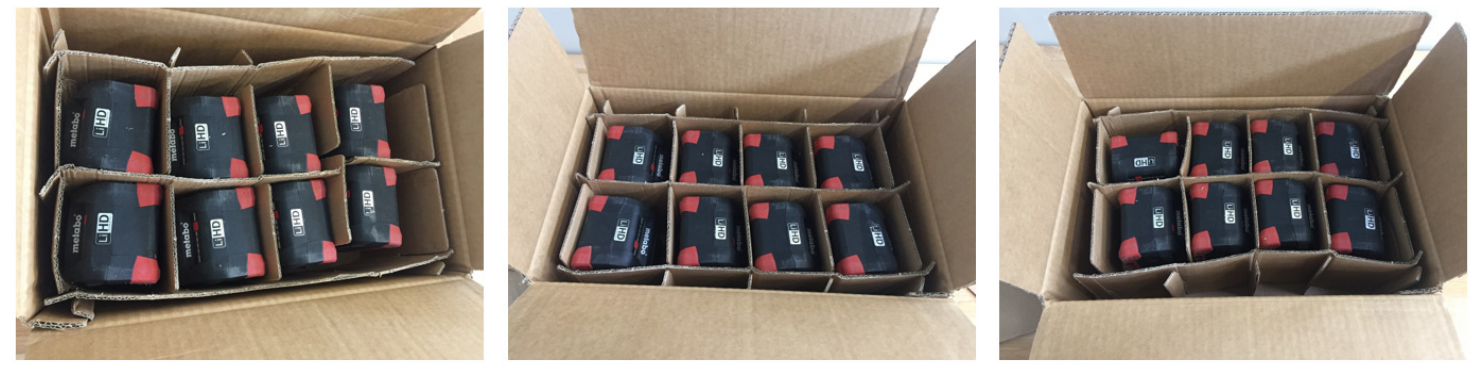

Figure 2. Damages (DGR, ISTA, FedEx).

The number and position of the drops is significantly different in case of the examined packaging system. Surprisingly, the test according to dangerous goods regulations gave the most favorable result despite the higher drop height, but the number and position of the drops differ fundamentally.

\section{Summary}

The test series examined if the tests according to DGR, parcel delivery and ISTA standards show similar or very different results. The results proved that the height of drop is surprisingly not the strongest influencing factor of the damages, rather the number of drops. This is probably explained by the fact that a minor damage occurring at the first drop escalates by increasing the number of drops. It is of course not possible to evaluate the individual types of packaging the same way. For instance, in the case of the plastic jerrycan dropping to the bottom edge is a critical position, since the weld seam at the closure of the injection moulding often causes longitudinal rifts, but this phenomenon is also highly dependent of the drop height. In case of plastic bags DGR tests are quite mild and test according to ISTA and FedEx standards gave significantly worse result, despite the lower drop heights, because the drop position is also crucial in these cases. In the case of the steel drum DRG test clearly gave the worst result, since the diagonally drop on the cover edge is more critical than in the other two cases. Numerous further tests are needed in the future so that these perceptions could be proved for several cases. This study has also pointed out the importance of choosing test moments and the order of them and the effect it has on the result. It is therefore crucial to choose the 'right' test protocol along with an understanding of the damage mechanisms, which are different for different materials and package constructions as well as transport conditions. The single package delivery of dangerous goods will probably need higher test demands.

\section{Acknowledgements}

The author acknowledges the financial support of this research by the Project EFOP-3.6.1-162016-00017. Internationalization, initiatives to establish a new source of researchers and graduates, and development of knowledge and technological transfer as instruments of intelligent specializations at Széchenyi István University.

\section{References}

[1] FEFCO Annual Statistics 2006.

[2] FEFCO Annual Statistics 2016. 
[3] ISTA 6: Amazon.com Over Boxing e-Commerce fulfilment for parcel delivery shipment

[4] Singh SP, Burgess GJ, Singh J, Kremer M. Measurement and analysis of the next-day air shipping environment for mid-sized and lightweight packages for DHL, FedEx and United Parcel Service. Packaging Technology and Science 2006a; 19, pp. 227-235, DOI: 10.1002/pts.726.

[5] Garcia-Romeu-Martinez MA, Singh SP, Cloquell-Ballester VA, Saha K. Measurement and Analysis of International Air Parcel Shipping Environment for DHL and FedEx between Europe and United States. Packaging Technology and Science 2007; 20, pp. 421-429.

[6] Böröcz P, Singh SP. Evaluation of Distribution Environment in LTL Shipment Between Central Europe and South Africa," Journal of Applied Packaging Research: Vol. 7, No. 2, Article 3. DOI: 10.14448/japr.04.0003

[7] Singh SP, Singh J, Stallings J, Burgess G, Saha K. Measurement and analysis of temperature and pressure in high altitude air shipments. Packaging Technology and Science 2010; 23, pp. 35-46.

[8] Appleton, D. A Study of package drops in global distribution environment, Thesis, Rochester Institute of Technology, 1997

[9] Stevenson AM. Free-fall drops, tosses and impacts measured in the small parcel international overnight air distribution environment Thesis, Rochester Institute of Technology, 1997.

[10] Zhong C, Li J, Kawaguchi K, Saito K, An H. Measurement and analysis of shocks on small packages in the express shipping environment of China. Packaging Technology and Science, 2016; 29, pp. 437-449.

[11] Menrad A, Goedecke T, Wagner MH. Drop test of plastic packagings-Correlation with material parameters and change of packaging behaviour after impact of standard liquids. Packaging Technology and Science, 2014; 27, pp. 479-493.

[12] Smithers P. The future of e-commerce packaging to 2022 Leatherhead, UK, 2017.

[13] Schultz J. Will e-commerce drive growth? Corrugated Today 2017; 13(4).

[14] Yam KL. The Wiley encyclopedia of packaging technology. Wiley, USA, 2009.

[15] Koning J. Corrugated Crossroads: A Reference Guide for the Corrugated Containers Industry, TAPPI Press, Atlanta, GA, 1995.

[16] Kellicutt KQ, Landt EF. Strength evaluations of corrugated containers by the drop test method, Tappi 1956; 39(9).

[17] Kellicutt KQ. Structural design notes for corrugated containers. Note No. 19: Drop-testing technique for boxes-Part I Package Engineering 1960a; 5(8), pp. 110-111.

[18] Kellicutt KQ. Structural design notes for corrugated containers. Note No. 20: Drop-testing technique for boxes-Part I Package Engineering 1960b; 5(10), pp. 118-119.

[19] Poustis J. Corrugated fibreboard packaging in Paper and paperboard packaging technology edited by Mark J Kirwan; ISBN 1-4051-2503-9, 2005.

[20] ASTM D5276: Standard test method for drop test of loaded containers by free fall.

[21] ISO 2248: Packaging - Complete, filled transport packages - Vertical impact test by dropping.

[22] ASTM D880: Standard test method for impact testing for shipping containers and systems.

[23] TAPPI T 802: Drop test for fiberboard shipping containers.

[24] ASTM D4003: Standard test methods for programmable horizontal impact test for shipping containers and systems.

[25] ISTA 3A: Packaged-products for parcel delivery system shipment $70 \mathrm{~kg}(150 \mathrm{lb})$ or less.

[26] ISO 2233: Packaging - Complete, filled transport packages and unit loads - Conditioning for testing. 